Efek Pemikatan (Attraction Effect) dan Bias Status Quo Sebuah Eksperimen

Dalam Perilaku Pengambilan Keputusan Portofolio Keuangan

\title{
EFEK PEMIKATAN (ATTRACTION EFFECT) DAN BIAS STATUS QUO SEBUAH EKSPERIMEN DALAM PERILAKU PENGAMBILAN KEPUTUSAN PORTOFOLIO KEUANGAN
}

\author{
Bayu Laksma Pradana \\ Sekolah Tinggi Ilmu Ekonomi Wiyatamandala \\ bayu@wym.ac.id
}

\begin{abstract}
The reference dependent preference plays a significant role in individual choice behavior. Introducing a third option which is asymmetrical dominated to the dominating option can influence one's decision. The status quo, endowment and attraction or decoy effect are the main noises. Such noises are proof to counter the rational choice theory. This paper tries to observe the status quo and decoy effect. Existence of those two effects are examined in experimental observation with 32 respondents. Questionnaires are set for respondents to dig information about how their answers contain choices. Two and three varies alternatives are presented to see respondent choice feedback when a third inferior alternatif is available. The result shows respondent tendency to switch options when status quo becomes a reference point.
\end{abstract}

Keywords: Reference Dependent, Choice Behavior, Portfolio, Status Quo Bias, Attraction Effect, Decoy Effect, Loss Aversion

\begin{abstract}
ABSTRAK
Teori reference dependent preference memainkan peran yang signifikan didalam perilaku memilih individu. Dengan memperkenalkan pilihan "ketiga" yang merupakan pilihan asymmetrical dominated akan mempengaruhi pengambilan keputusan seseorang. Status quo, endowment dan decoy effect merupakan distraksi (noise) yang mempengaruhi pikiran dan berpotensi merubah pilihan seseorang. Distraksi ini merupakan bukti teori yang berseberangan dengan teori rational choice. Studi ini mengobservasi keberadaan status quo dan decoy effect. Eksistensinya diuji dengan menggunakan observasi eksperimental dengan melibatkan 32 responden. Eksperimental menggunakan kuesioner yang berisi pilihan-pilihan. Dua dan tiga alternatif yang berbeda disajikan untuk melihat umpan balik, ketika pilihan yang lebih inferior tersedia. Hasilnya menunjukkan bagaimana responden mempunyai kecenderungan untuk menukar pilihannya ketika status quo menjadi reference point.
\end{abstract}


Kata kunci: Ketergantungan Referensi, Perilaku Pilihan, Portofolio, Bias Status Quo, Efek Atraksi, Efek Umpan, Penghindaran Kerugian

\section{PENDAHULUAN}

Beberapa penelitian eksperimental khususnya dalam bidang psikologi dan ekonomi keperilakuan telah menunjukan bahwa setiap orang berperilaku secara berbeda tergantung pada reference (referensi). Gejala ini terlihat jelas dalam kasus endowment effect dan default effect. Sebagai contoh seseorang lebih memilih barang A dibandingkan barang $B$ jika ia sebelumnya memiliki barang A. Begitu pula jika terdapat barang $\mathrm{C}$ dan $\mathrm{D}$ seseorang akan lebih memilih barang $\mathrm{D}$ jika ia memiliki barang itu sebelumnya. Banyak observasi dalam riset memberi konfirmasi bahwa seseorang akan memberi penghargaan lebih terhadap barang yang dimilikinya dibanding jika belum memiliki "endowment effect" (Richard Thaller). Teori lain berkaitan dengan loss aversion, dimana seseorang akan menilai kerugian dalam proporsi yang lebih besar dibanding dengan keuntungan. Begitu pula status quo bias di mana seseorang akan cenderung terjebak pada pilihan status quo ketika ia dihadapkan pada beberapa pilihan baru.

Temuan dalam penelitian experimental menunjukan:

1. Bahwa orang lebih menyukai pilihan status quo nya
2. Adanya pilihan status quo dimungkinkan dapat merubah preferensi pilihan seseorang, walaupun pilihan status quo itu sendiri tidak dipilih.

Misalnya seseorang telah memiliki barang A, lalu ia ditawari 3 barang termasuk didalamnya barang $\mathrm{A},\{\mathrm{A}, \mathrm{B}, \mathrm{C}\}$. Ia dapat memilih barang B. Namun ketika barang yang telah dimilikinya dirubah menjadi barang $\mathrm{K}-\{\mathrm{K}, \mathrm{B}, \mathrm{C}\}$, pilihannya dapat berubah menjadi barang $\mathrm{C}$. Hal ini terlihat jelas pada kasus attraction effect. Kasus diatas menunjukan bagaimana sebuah pilihan rasional dapat berubah kebalikannya ketika diberikan pilihan inferior. Ini menjelaskan bahwa adanya penyimpangan dari rational choice theory (independenceof irrelevant alternatives) dimana preferensi diantara berbagai pilihan terbebas dari ada atau tidaknya pilihan lain. Perdebatan argumentasi dapat terjadi karena dalam literatur reference dependent tidak disangkut pautkan dengan endowment (kepemilikan), namun hanya sebuah teori dalam menjelaskan decoy effect (efek pengalihan). Argumen yang lebih meyakinkan adalah pada contoh-contoh tersebut, alternatif ke-3 digunakan sebagai reference point (titik 


\section{Efek Pemikatan (Attraction Effect) dan Bias Status Quo Sebuah Eksperimen}

\section{Dalam Perilaku Pengambilan Keputusan Portofolio Keuangan}

referensi) dimana titik ini dinamakan "endowment" ataupun bukan, tidak menjadi masalah Attraction Effect dapat dijelaskan oleh teori reference dependent jika pemikat (decoy) ditaruh sebagai titik referensi (reference point) dan mempengaruhi keputusan untuk memilih. Alternatif yang bersifat inferior dapat ditempatkan dalam pilihan sebagai reference point. Jika seperti ini kasusnya maka kita dapat mengidentifikasi reference point tanpa adanya pengaruh luar. Kita juga ingin mengetahui apakah yang akan terjadi jika dalam pilihan tersebut terdapat reference point yang bersifat endowment ataupun decoy. Jika pembuat keputusan tidak memiliki referensi yang pasti maka model reference dependent tidak akan terbukti. (Kahneman \& Tversky, 1991) menunjukan bahwa referensi mengacu pada endowment dari pengambil keputusan.

Tujuan dari penelitian ini adalah:

1. Memisahkan pengaruh endowment effect

\section{TELAAH LITERATUR}

Riset mengenai Reference dependent preference dikemukakan oleh peraih Nobel Daniel (Kahneman \& Tversky, 1991), dalam artikel ilmiahnya berjudul "Loss Aversion in Riskless Choice". Secara singkat teori ini mengetengahkan bagaimana seseorang dalam membuat keputusan seringkali sadar dan decoy effect dalam perilaku penentuan pilihan portofolio dan uang.

2. Melakukan investigasi penentuan titik referensi dalam situasi dimana endowment dan decoy berada bersama didalam alternatif pilihan yang tersedia

Dalam rangka tujuan diatas maka diadakan eksperimen terhadap pengambilan keputusan individu menggunakan 2 tipe pertanyaan. Pertama, responden dihadapkan pada situasi untuk membuat pilihan tanpa dimulai dari endowment. Kemudian kedua, ia akan ditanya kembali untuk memilih pilihan yang sama dengan situasi dimana salah satu pilihan menjadi endowment. Data eksperimental yang didapat menunjukan bahwa status quo memiliki pengaruh yang lebih kuat dalam perilaku keputusan memilih dari individu dibanding dengan decoy. Lebih jauh lagi, status quo menunjukan hasil yang lebih baik sebagai reference point, meskipun dalam pilihan tersebut terdapat status quo dan decoy.

atau tidak sadar, bergantung pada pembanding (reference point). Reference point ini sering kali berupa keadaan saat ini (status quo), keinginan masa depan, ataupun keadaan sosial dan sebagainya. Contoh paling sederhana untuk menggambarkan keadaan ini adalah jika seseorang dijanjikan 
untuk mendapat uang Rp.100.000,-- maka dirinya akan berpikir bahwa dimasa depan ia akan bertambah kaya sejumlah uang tersebut. Namun ketika kenyataannya ia hanya mendapatkan Rp. 50.000,-. Kenyataannya ia masih mendapatkan uang tapi kali ini ia merasa tidak puas. Informasi Rp. 100.000 adalah reference point yang menjadi pembanding. (Kahneman \& Tversky, 1979) juga menyebutkan prospect theory sangat berkaitan dengan reference dependfent theory. Prospect theory atau loss aversion theory menyatakan bahwa dihadapkan pada pilihan dan pembuatan keputusan, seseorang cenderung memberi nilai berbeda pada persepsi keuntungan dan kerugian. Persepsi kerugian sering kali diberi bobot lebih dibanding dengan keuntungan. Seseorang yang mengalami kerugian Rp 100.000, secara cepat dapat terkompensasi dengan keuntungan Rp. 2000.

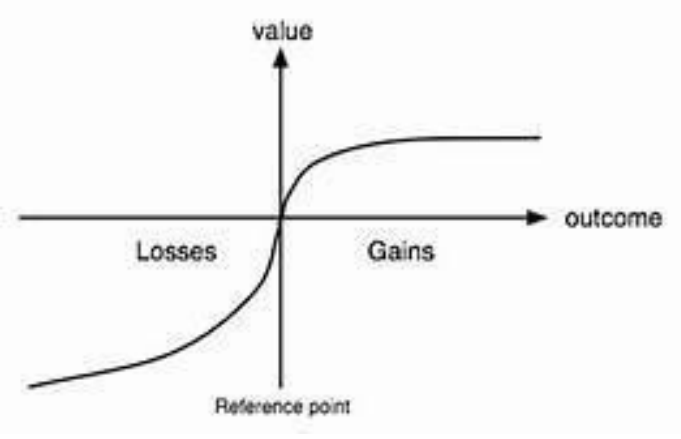

Gambar. 1 Prospect Theory

Dua hal yang dapat menjadi contoh reference dependent preference adalah endowment effect dan status quo bias. Endowment effect adalah kecenderungan seseorang untuk menghargai/ menilai

\section{Status Quo Bias}

Status quo bias adalafh sebuah fenomena penyimpangan (bias) pikiran dimana ketika seorang individu dihadapkan pada keputusan untuk memilih, ia cenderung untuk tidak berubah dari pilihan yang sudah pernah dibuatnya. Semakin banyak alternatif pilihan yang disodorkan kepadanya maka semakin sesuatu yang dimilikinya melebihi nilai pasarnya. Konsep ini diperkenalkan oleh seorang peraih nobel (Thaler, 2016) dalam eksperimen mug nya yang terkenal.

besar kecenderungan dirinya untuk tetap bertahan pada pilihan sebelumnya. Riset awal status quo bias dilakukan oleh Samuelson dan Zeckhauser (1988), yang melakukan penelitian pada pemilihan health plan program pada para pensiunan mengungkap bahwa status quo bias adalah 
sesuatu yang patut diperhitungkan. Keduanya mengatakan bahwa didalam keputusan yang nyata selalu ada opsi tidak memilih atau mempertahankan pilihan yang lalu. (Li, Ren, MA, \& Liu, 2009), mengungkap pengaruh efek framing, emosi investor dan struktur informasi terhadap status quo bias. Hasil penelitian mereka bahwa status quo lebih terlihat pada framing perbedaan harga (price differential frame) dibanding dengan framing rasio pada portofolio. Mereka juga menyatakan keberadaan status quo bias pada 3 keadaan emosi, positif, negatif dan netral. Bekir

\section{Attraction (Decoy) Effect}

Dalam marketing Attraction effect adalah fenomena dimana konsumen akan cenderung merubah preferensinya dalam memilih 2 opsi ketika dihadirkan pilihan ketiga. Misalnya, seseorang yang ditawari 2 buah es krim Es krim A - 2 scoops dengan harga Rp. $2000,-$
(2020), melakukan penelitian antara preferensi risiko dengan status quo. Hasilnya menunjukan bahwa adanya korelasi antara perilaku terhadap risiko dengan adanya status quo bias dan hal ini berakibat pada proses pengambilan keputusan. (Krieger \& Felder, 2013), menemukan kecenderungan status quo dalam pengambilan kebijakan polis asuransi kesehatan. Dalam hubungannya dengan framing, peneliti tidak menemukan keberadaannya dikarenakan subyek penelitian melakukan pengulangan keputusan pada periode berikutnya.

Es krim B - 3scoops dengan harga Rp. 3000,Dalam hal ini secara teori kemungkinan orang tersebut memilih adalah 50\% untuk setiap pilihan. Namun diperkenalkan pilihan baru.Untuk menggangu keputusan rasionalnya maka dapat ditawarkan pilihan ke tiga Es krim C - 1 scoop dengan harga Rp. $2000,-$ 


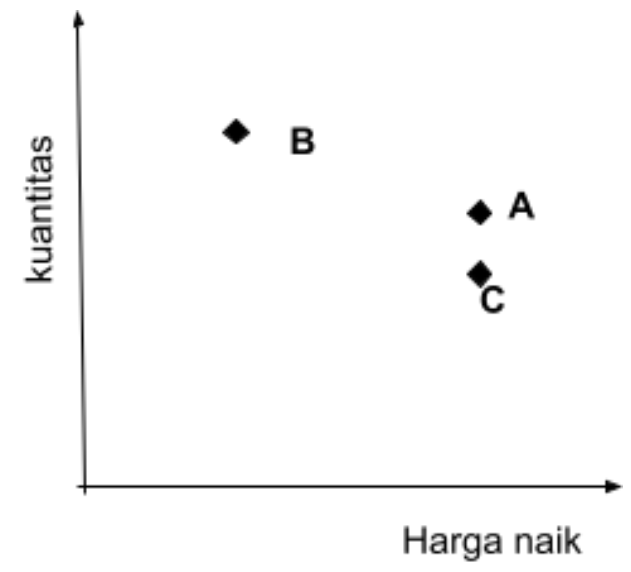

\section{Gambar 2. Decoy Effect}

Sehingga probabilitas untuk setiap pilihan adalah menjadi 33,3\%. Pilihan $\mathrm{C}$ inferior adalah pilihan yang tidak untuk dipilih, namun probabilitasnya akan menambah pada pilihan A. Pada akhirnya yang terjadi adalah pilihan $\mathrm{A}-66,6 \%$ dan $\mathrm{B} 33,3 \%$. Dalam kasus ini dapat dikatakan $\mathrm{C}$ adalah dominated, dengan kata lain asymmetric dominated dalam teori sering disebut sebagai decoy effect atau asymetric

\section{METODOLOGI PENELITIAN}

Eksperimen dilakukan dengan melakukan penyebaran kuesioner yang berisi pertanyaan untuk melakukan mengetahui apakah status quo lebih mempengaruhi pemilihan dibanding dengan adanya pemikat (decoy). Langkah pertama akan dilontarkan pertanyaan kepada responden 2 pilihan kombinasi antara portofolio dan uang. Sebagai contoh pilihan A dan B. Jika salah satu pilihan telah dipilih maka akan diperkenalkan dengan pilihan lanjutan $\mathrm{C}$. dominance theory Slaughter, Kausel, Quinones (2010) melakukan penelitian apakah individu dapat menggunakan decoy effect untuk mempengaruhi pilihan orang lain. Dalam penelitiannya responden diminta untuk memilih satu dari dua kandidat karyawan. Setelah itu mereka diminta untuk menambah 1 dari 3 karyawan inferior untuk disandingkan (decoy) untuk mengubah keputusan orang lain.

Pilihan C ini didominasi oleh pilihan lainnya. Langkah selanjutnya, pertanyaan yang sama juga dilontarkan apakah responden akan memilih 2 alternatif dimana pilihan C ditetapkan sebagai endowment. Jika pilihan endowment ini diperkenalkan akankah responden mengalami masalah didalam pemilihan alternatif. Studi ini dilakukan secara online dengan menggunakan google form terhadap responden yang dipilih secara acak. Jumlah responden yang mengisi 
kuesioner adalah 40 orang dengan sedapat mungkin dilakukan variasi terhadap jenis kelamin, umur, latar belakang pendidikan, pekerjaan dan lain-lain. Setiap responden menjawab 5 pertanyaan singkat. Sebagai timbal balik responden diberikan sejumlah uang. Dari 5 pertanyaan yang diajukan responden diminta untuk membuat keputusan antara 2 sampai 3pilihan. Setiap pilihan berisi kombinasi uang dan beberapa portofolio. Pertanyaan yang memiliki tiga pilihan dapat berupa decoy, status quo atau keduanya sekaligus. Ketika responden dihadapkan pada status quo, mereka ditanya untuk mempertahankan atau merubah pilihan dari 1 atau 2 alternatif tersedia. Apakah decoy dan

\section{HASIL DAN PEMBAHASAN}

Tabel 1 menunjukan jumlah pertukaran dari pilihan ketika decoy atau status quo diperkenalkan. Sebagai informasi decoy ini merupakan pilihan asymetrical dominated status quo adalah reference point? Jika pilihan decoy adalah reference point, maka pilihan seharusnya sama diantara 2 pertanyaan ini. Namun, jika status quo sebagai reference poin maka kita harus melakukan observasi kepada pilihan y dibanding dengan pilihan pertama.

Pertanyaan lain, apa yang terjadi jika terdapat decoy dan status quo pada saat bersamaan. Perhatikan skenario berikut:

- Responden diminta memilih antara $\mathrm{x}, \mathrm{y}$ dan $\mathrm{z}$ dimana pilihan $\mathrm{z}$ adalah asymetrical dominated dari y.

- Yang kedua, y merupakan endowment lalu diminta memilih dari alternatif lagi.

dari alternatif yang tidak dipilih. Persentase status pertukaran ketika status quo diperkenalkan adalah 24\% sedangkan $15 \%$ untuk decoy diperkenalkan.

\section{Tabel 1. Hasil pertukaran Decoy dan Status Quo}

\begin{tabular}{|l|c|c|c|l|l|l|l|l|}
\hline & \multicolumn{2}{|c|}{ P1 } & \multicolumn{2}{c|}{ P2 } & \multicolumn{2}{c|}{ P3 } & \multicolumn{2}{c|}{ Total } \\
\hline Responden & D & SQ & D & SQ & D & SQ & D & SQ \\
\hline Pertukaran & 31 & 26 & 15 & 13 & 8 & 5 & 9 & 9 \\
\hline $\begin{array}{l}\text { Non } \\
\text { Pertukaran }\end{array}$ & 10 & 10 & 5 & 7 & 2 & 3 & 2 & 2 \\
\hline
\end{tabular}

Jika kita lihat sebuah kelompok pilihan $\mathrm{x}, \mathrm{y}$ dan $\mathrm{z}$ dimana $\mathrm{z}$ merupakan asymetrically dominated dari y. Kita akan melihat pengaruh bagaimana jika alternatif y merupakan status quo. Sebagai catatan pilihan status quo mendominasi decoy. Jika terdapat pilihan 
endowment tidak mempengaruhi perilaku menjadi

reference

point. keputusan memilih, pilihan decoy tentu saja

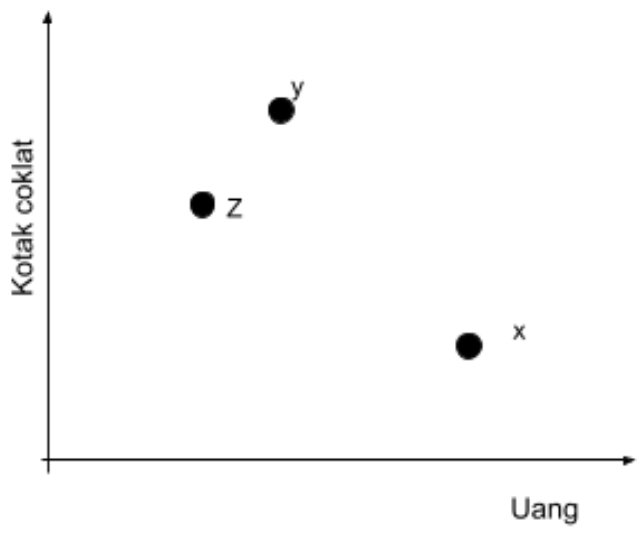

Gambar 3. Plot hasil

Perilaku keputusan memilih pasti akan sama diantara 2 pertanyaan tersebut. Pada tabel 2 kita dapat melihat bahwa kejadian yang telah diterangkan diatas tidak selalu terjadi. 41 orang tidak merubah keputusannya ketika pilihan y menjadi endowment. 6 orang merubah keputusannya sedangkan 2 orang lebih memilih $\mathrm{x}$.

Tabel 2. Detil pertukaran dan non pertukaran

\begin{tabular}{|c|c|c|c|c|}
\hline & & P1 & P2 & Total \\
\hline Pertukaran & $\mathrm{x}-\mathrm{x}$ & 14 & 2 & 16 \\
\hline & $\mathrm{y}-\mathrm{y}$ & 3 & 22 & 25 \\
\hline $\begin{array}{c}\text { Non } \\
\text { pertukaran }\end{array}$ & $\mathrm{x}-\mathrm{y}$ & 2 & 4 & 6 \\
\hline & $\mathrm{y}-\mathrm{x}$ & 2 & 0 & 2 \\
\hline
\end{tabular}

\section{SIMPULAN}

Adanya status quo bias dan decoy effect mempengaruhi perilaku pilihan individu. Kedua efek tersebut menjadi pemicu berpindahnya pilihan yang satu ke yang lain ketika pilihan ketiga baik yang bersifat status quo ataupun pilihan yang memiliki sifat asymmetric dominated diperkenalkan. Hal ini mengindikasikan bahwa adanya reference point dalam pilihan menimbulkan perubahan probabilitas pada pilihan-pilihan yang ada. Dibandingkan dengan decoy effect, status quo bias lebih memiliki tingkat keberhasilan pertukaran pilihan. Hal ini sejalan dengan teori loss aversion yang dikemukakan 
(Kahneman \& Tversky, 1991). Adapun saran yang di berikan dalam sebuah penelitian ini adalah perlu mempertajam dengan menambah jumlah sampel/responden untuk lebih mempertajam temuan yang didapat.

\section{DAFTAR PUSTAKA}

Ackert, L. F., \& Deaves, R. (2009). Behavioral Finance: Psychology, Decision making and Market Independence. Canada: Cengage Learning.

Bruner, J., Calegari, F., \& Handfield, T. (2020). Evolution of Endowment Effect. Evolution and Human Behavior., 87-95.

Charles, A., Darne, O., \& Kim, J. H. (2017). Adaptive Markets Hypothesis for Islamic Stock Indices: Evidence from Dow Jones Size and Sector-Indices. International Economics, 100-112.

Ciumara, T. (2014). Factor Influencing Individual Financial Decision: A Literature Review. Economy and Management (GIDNI), 420-427.

Coursey, D. L., Hovis, J. L., \& Schulze, W. D. (1987). The Disparity Between Willingnes to Accept and Willingness to Pay Measure of Value. Quarterly Journal of Economic., 679 - 690.

Kahneman, D., \& Tversky, A. (1979).

Prosperct Theory: An Analysis of Decision Under Risk. Econometrica,
Selain itu, adanya bias lain, seperti Anchoring sebaiknya dapat diperkenalkan. Metode eksperimental yang lebih rumit sangat disarankan untuk melakukan observasi lebih lanjut.

263-291.

Kahneman, D., \& Tversky, A. (1990). Experimental Test of The Endowment Effect and Coase Theorem. ournal of political economy, 1325 - 1348.

Kahneman, D., \& Tversky, A. (1991). Anomalies The Endowment Effect, Loss Aversion, and Status Quo Bias. . Journal of Economic Prespectives, 5, 193 - 206.

Kahneman, D., \& Tversky, A. (1991). Loss Aversion in Riskless Choice: A Reference-Dependent Model. The Quarterly Journal of Economics, Vol.106 , 1039-1061.

Krieger, M., \& Felder, S. (2013). Can Decision Biases Improve Insurance Outcomes? An Experiment on Status Quo Bias in Health Insurance Choice. International Journal of Environmental Research and Public Health, 2560-2577.

Li, J., Ren, G., MA, Q., \& Liu, L. (2009). An experimental study on investors' status quo bias and its determinants. Front. Bus. Res. China 2009, 3(4), 
$543-565$.

Lo, A. W. (2017). Adaptif Market. New Jersey: Princeton University Press.

Shiller, R. J. (2000). Irrational Exuberance. New Jersey: Princeton University Press. New Jersey: Princeton University Press.

Thaler, R. H. (1988). Anomalies : The
Winners Curse (Vol. 2). Journal of Economic Perspective. Journal of Economic Perspective, Vol.2 No.1, 191-202.

Thaler, R. H. (2016). Misbehaving : The Making of Behavioral Economic. New York: W.W. Norton \& Company. 